\title{
Manual Planimetry of the Medial Temporal Lobe Versus Automated Volumetry of the Hippocampus in the Diagnosis of Alzheimer's Disease
}

Manuel Menéndez González ${ }^{1}$, Esther Suárez-Sanmartin ${ }^{1}$, Ciara García ${ }^{1}$, Pablo MartínezCamblor $^{2}$, Eric Westman ${ }^{3}$, Andy Simmons ${ }^{4}$

1. Neurology, Hospital Universitario Central de Asturias 2. Estadística, Hospital Universitario Central de Asturias 3. Department of Neurobiology, Care Sciences and Society, Karolinska Institutet 4. Institute of Psychiatry, King's College London

$\square$ Corresponding author: Manuel Menéndez González, manuelmenendezgonzalez@gmail.com Disclosures can be found in Additional Information at the end of the article

\section{Abstract}

Introduction:

Though a disproportionate rate of atrophy in the medial temporal lobe (MTA) represents a reliable marker of Alzheimer's disease (AD) pathology, measurement of the MTA is not currently widely used in daily clinical practice. This is mainly because the methods available to date are sophisticated and difficult to implement in clinical practice (volumetric methods), are poorly explored (linear and planimetric methods), or lack objectivity (visual rating). Here, we aimed to compare the results of a manual planimetric measure (the yearly rate of absolute atrophy of the medial temporal lobe, 2D-yrA-MTL) with the results of an automated volumetric measure (the yearly rate of atrophy of the hippocampus, 3D-yrA-H).

Methods:

A series of 1.5T MRI studies on 290 subjects in the age range of $65-85$ years, including patients with $\operatorname{AD}(n=100)$, mild cognitive impairment $(M C I)(n=100)$, and matched controls $(n=90)$ from the AddNeuroMed study, were examined by two independent subgroups of researchers: one in charge of volumetric measures and the other in charge of planimetric measures.

Results:

The means of both methods were significantly different between $\mathrm{AD}$ and the other two diagnostic groups. In the differential diagnosis of $\mathrm{AD}$ against controls, 3D-yrA-H performed significantly better than 2D-yrA-MTL while differences were not statistically significant in the differential diagnosis of $\mathrm{AD}$ against MCI.

Conclusion:

Automated volumetry of the hippocampus is superior to manual planimetry of the MTL in the diagnosis of AD. Nevertheless, the 2D-yrAMTL is a simpler method that could be easily implemented in clinical practice when volumetry is not available.

How to cite this article

Menéndez gonzález M, Suárez-sanmartin E, García C, et al. (March 26, 2016) Manual Planimetry of the Medial Temporal Lobe Versus Automated Volumetry of the Hippocampus in the Diagnosis of Alzheimer's Disease. Cureus 8(3): e544. DOI 10.7759/cureus.544 
Categories: Neurology, Psychiatry, Radiology

Keywords: mri, planimetry, volumetry, alzheimer's disease, medial temporal lobe, hippocampus, addneuromed study

\section{Introduction}

Age-associated differences are detected in the medial temporal lobe (MTL) with an acceleration of atrophy starting around 72 years of age in healthy people [1-2]. In Alzheimer's disease (AD), a disproportionate rate of atrophy in the medial temporal lobe (MTA) represents a reliable marker of the neurodegenerative process underlying clinical symptoms [3]. Then, ageassociated changes in healthy people are modest, and the rate of atrophy over time is relatively slow, with a mean rate of tissue loss about 1\% per year [1-2]. Accelerated MTA is a consistent finding in $\mathrm{AD}$ and mild cognitive impairment (MCI), with rates of about $2.5 \%$ in stable $\mathrm{MCI}$ and up to $4 \%$ in $\mathrm{AD}$ and $\mathrm{MCI}$ transitioning to $\mathrm{AD}$ (MCI progressors) [2, 4].

Numerous studies worldwide have shown that MRI is useful for detecting atrophy of structures in the MTL to discriminate early AD from controls and MCI, and have also demonstrated the potential for prediction of conversion from MCI to AD [5-12]. The European Union AddNeuroMed program and the US-based Alzheimer Disease Neuroimaging Initiative (ADNI) are two large multicenter initiatives designed to collect and validate biomarker data for AD that have allowed an impressive number of studies on brain atrophy in AD and MCI in the last decade. Both the AddNeuroMed and the ADNI cohorts showed very similar patterns of atrophy in MCI and AD [13].

The new diagnostic criteria for both $\mathrm{AD}$ and MCI due to AD incorporate MTA as a neuronal loss marker [14]. Thus, the time is now ripe for the quantification of MTL structures to become a component of the evaluation of patients with cognitive impairment.

Several methods have been proposed for quantifying atrophy of MTL structures using structural neuroimaging, including visual rating (VR), volumetry (3D), planimetry (2D), and linear measures (1D). In short, volumetry is based on the reconstruction of the volumes of regions of interest (ROIs), by integrating the area of brain structures across several MRI slices. Summed ROI over the slices is used to count the number of voxels and, ultimately, produce a volumetric measurement. The volumetric analysis provides an accurate and detailed measure of a predetermined ROI. For AD, the most commonly studied structure in the MTL is the whole hippocampus. While studies have established this clear finding of MTA in AD, hippocampal volumetry has not yet become a routine part of the diagnostic workup for neurodegenerative diseases. Despite the advantages, this method requires individual segmentation of structures within the MTL, which may also vary considerably across different operators, depending upon their training and experience. Once trained, segmentation of the hippocampus takes approximately 20-30 minutes, depending on the user's experience, which limits its use in routine clinical practice [15]. An alternative is the use of automated MRI methods based on individual brain atlases that are able to capture signs of brain atrophy. FSL, SPM, and FreeSurfer packages are the most utilized methods in recent research for measuring brain atrophy. These packages allow for completely automated, user-independent calculations of regional brain volumes [16-19].

VR consists of semi-quantitative and subjective rating of ROIs, often on a single MRI slice. VR approaches are quick and can be assessed on large numbers of scans easily. Unfortunately, there is significant inter-observer variation [20-22]. Such poor inter-rater reliability is a major limitation for implementing VR in the clinical setting.

Linear methods (1D) use simple linear measures of the width or height of ROIs measured on one single MRI slice. Linear measures are objective and easy to obtain using any software for 
visualizing radiological images. A positive feature is that linear measures are available not only for MRI but for CT scans as well. Some studies have attempted to define sentinel changes that would allow the use of linear measurements of the hippocampus or the temporal horn to support clinical decision making. These studies have yielded variable results, with sensitivities ranging from $33 \%$ to $93 \%$ and specificity of up to $95 \%$ [23-25].

Planimetric measures are based on the area of ROIs measured on one single MRI slice. Several planimetric measures have proven to be easy to use in a clinical setting and to have good reproducibility [26-28]. Importantly, both the linear and the planimetric measures have the potential to be applied to computed tomography (CT) images, the most widely available imaging technique in primary health care, where most of the dementia evaluations take place [29]; it is often the first requested neuroimaging technique for routine assessment in many specialized centers.

An important limitation that obstructs the use of all these methods in clinical practice is the lack of normative values for interpretation. In addition, few studies have compared the performance of the different methods in the diagnosis of $\mathrm{AD}$ [30-33], and none of them included planimetric methods. Here, we aim to compare the results of one planimetric measure of the medial temporal lobes (the yearly rate of absolute atrophy of the MTL, 2D-yrA-MTL) with the results of automated volumetry of the hippocampi (the yearly rate of absolute atrophy of the hippocampus, 3D-yrA-H) in the differentiation of $\mathrm{AD}$ against controls and MCI patients.

\section{Materials And Methods}

\section{Patients and controls}

A series of MRI studies on 290 subjects in the age range of 65-85 years, including patients with $\operatorname{AD}(n=100), \operatorname{MCI}(n=100)$, and matched controls $(n=90)$ from the multi-center Pan-European AddNeuroMed study were included in this study [34].

All subjects underwent baseline and cognitive testing at baseline and every three months up to one year. The clinical assessment and cognitive testing of the AddNeuroMed subjects followed a standard protocol previously described [34]. Assessments included a structured interview including a detailed case and family history, the Cambridge Examination for Mental Disorders of Older People (CAMDEX), cognitive testing with mini-mental state examination (MMSE), Alzheimer Disease Assessment Scale - Cognitive (ADAS-cog), and stage of dementia with the Clinical Dementia Rating Scale sum of boxes (CDR-SOB) score. Written consent was obtained where the research participant had the capacity, and in those cases where there was dementia-compromised capacity, then assent from the patient and written consent from a relative, according to local law and process, was obtained. The detailed inclusion and exclusion criteria, as well as the diagnostic criteria, have been previously reported in other AddNeuroMed studies [34-36].

\section{Magnetic resonance imaging}

Two 1.5T MRI studies were performed on all the patients, namely, baseline and follow-up (12 months) using the same machine and protocol. The imaging protocol included a highresolution sagittal 3D T1-weighted magnetization-prepared rapid gradient-echo (MP-RAGE) volume and axial proton density/T2-weighted fast spin echo images.

\section{Neuroimaging analyses procedures}

Researchers who participated in this study were divided into two independent subgroups, each subgroup blinded to the results of the other subgroup. The first subgroup of researchers 


\section{Cureus}

performed volumetry of the hippocampus. First, we applied the FreeSurfer pipeline (version 4.5.0) to the MRI images to produce regional cortical thickness and subcortical volumetric measures [37-38]. All volumetric measures from each subject were normalized by the subject's intracranial volume. Therefrom, we can compute the mean 3D-yrA-H using the following formulae: 3D-yrA-H = [(basal volume of both hippocampi) - (follow-up volume of both hippocampi)] x 1200 / [(months between MRI studies) x (basal volume of both hippocampi)]. Volumes from the left and the right hemisphere were averaged together. The second subgroup of researchers traced the areas needed to compute the 2D-yearly rate of atrophy of the medial temporal lobe (2D-yrA-MTL) as described previously [39]. Researchers used the free-hand tracing tool of the software Osirix to delineate the areas manually on one single coronal MRI slice passing through the interpeduncular fossa. The 2D-yrA-MTL consists of measuring the area of two brain regions on one single MRI coronal slide in T1-weighted sequence and then subtracting them. The two areas are (1) the MTL region (A) and (2) the parenchyma within the medial temporal region (B), including the hippocampus and the parahippocampal gyri (Figure 2). Therefrom, we can compute the mean $2 \mathrm{D}$-yrA-MTL using the formulae described in the new terminology on regional brain atrophy [39]: 2D-yrA-MTL = [(basal A+A'-B+B') - (follow-up $\left.\left.A+A^{\prime}-B^{\prime}+B^{\prime}\right)\right] \times 1200 /[($ months between MRI studies) x (basal A+A'-B+B')\}. Areas of the left and the right hemisphere were averaged together.

\section{Statistics}

As the main focus of the study was to compare two diagnostic procedures in $\mathrm{AD}$, we did not differentiate MCI into converters and non-converters and used all MCI subjects as a single group. Statistical analyses were performed using the $\mathrm{R}^{\mathrm{TM}}$ and Epidata ${ }^{\mathrm{TM}}$ software. T-test analyses were used to test for differences in continuous outcomes, such as MRI-based measures and age between $\mathrm{AD}, \mathrm{MCI}$, and controls. The Chi-square test was used to test for differences in categorical variables, such as gender. We then set best cut-off points of these methods in the diagnosis of AD against controls and against MCI based on Youden's index and computed the resulting sensitivity and specificity. Finally, we produced receiver operating characteristic (ROC) curves of both 2D-MTA and hippocampus volumetry in the differential diagnosis of AD vs. controls and AD vs. MCI and compared them using the Hanley and McNeil method for comparing the ROC curves.

\section{Results}

\section{Demographics}

Basic demographics and characteristics of the subjects in the different diagnostic groups are shown in Table 1.

\begin{tabular}{|c|c|c|c|}
\hline & Controls & $\mathrm{MCI}$ & Alzheimer's \\
\hline Gender (Female \%) & 53 & 49 & 64 \\
\hline Age in years & $74.26(5.22)$ & $74.10(5.12)$ & 74.21 (6.19) \\
\hline
\end{tabular}

\section{TABLE 1: Demographics}

Basic demographics and characteristics of the subjects in the different diagnostic groups: first row shows the percentage of females and second row shows the mean age and standard deviation. 


\section{Cureus}

There were no statistically significant differences in gender $(\mathrm{p}=0.242)$ and age $(\mathrm{p}=0.458)$ between groups.

\section{Comparison of means between diagnostic groups}

The means of 3D-yrA-H and 2D-yrA-MTL in the three diagnostic groups are shown in Table 2.

\begin{tabular}{|c|c|c|c|}
\hline & Controls & $\mathrm{MCl}$ & Alzheimer's \\
\hline 3D-yrA-H & $1.40 \%(0.25)$ & $1.82 \%(0,23)$ & $2.12 \%(0.20)$ \\
\hline 2D-yrA-MTL & $1.31 \%(0.27)$ & $1.79 \%(0.24)$ & $2.24 \%(0.23)$ \\
\hline
\end{tabular}

\section{TABLE 2: 3D-yrA-H and 2D-yrA-MTL}

Means and standard deviation of 3D-yrA-H and 2D-yrA-MTL in the three diagnostic groups.

Statistical analyses showed significant differences in all comparison of means of both methods between $\mathrm{AD}$ and the other two groups. Thus, the mean 3D-yrA-H was statistically different in AD compared with controls $(p=0.021)$ and MCI $(p=0.042)$, and the mean 2D-yrA-MTL was statistically different in AD compared with controls $(p=0.037)$ and MCI $(p=0.045)$.

\section{Performance in the diagnosis of Alzheimer's disease}

First, we set the best cut-off points for both methods in the diagnosis of AD versus controls and versus MCI based on Youden's index. Cut-off points are shown in Table 3. Table 3 also shows the resulting sensitivity and specificity values of each method using these cut-off points.

\begin{tabular}{|c|c|c|}
\hline & Alzheimer's vs Controls & Alzheimer's vs MCI \\
\hline 3D-yrA-H & $\begin{array}{l}\text { Cut-off: } 1.67 \% \text {; sensitivity: } 86.8 \% \text {; specificity: } \\
82.1 \%\end{array}$ & $\begin{array}{l}\text { Cut-off: 1.92\%; sensitivity: } 76.7 \% \text {; specificity: } \\
73.1 \%\end{array}$ \\
\hline $\begin{array}{l}\text { 2D-yrA- } \\
\text { MTL }\end{array}$ & $\begin{array}{l}\text { Cut-off: } 1.61 \% \text {; sensitivity: } 77.2 \% \text {; specificity: } \\
75.4 \%\end{array}$ & $\begin{array}{l}\text { Cut-off: } 1.96 \% \text {; sensitivity: } 71.8 \% \text {; specificity: } \\
68.9 \%\end{array}$ \\
\hline
\end{tabular}

\section{TABLE 3: Cut-off Points}

Best cut-off points for both methods in the diagnosis of AD versus controls and versus $\mathrm{MCl}$ based on Youden's index, besides the resulting sensitivity and specificity values.

Then, we computed ROC curves and the area under the curve (AUC) for each method. In the differential diagnosis of $\mathrm{AD}$ against controls, the area under the curve (AUC) for 3D-yrA-H was 0.902 (0.87 - 0.93) while that for 2D-yrA-MTL was 0.785 (0.73 - 0.84); differences were statistically significant $(\mathrm{p}<0.001$ ) (Figure 1). In the differential diagnosis of AD against MCI, the AUC for 3D-yrA-H was 0.702 (0.65-0.75) while that for 2D-yrAMTL was 0.661 (0.60-0.72); 


\section{Cureus}

differences were not statistically significant $(\mathrm{p}=0.228)$ (Figure 1$)$.

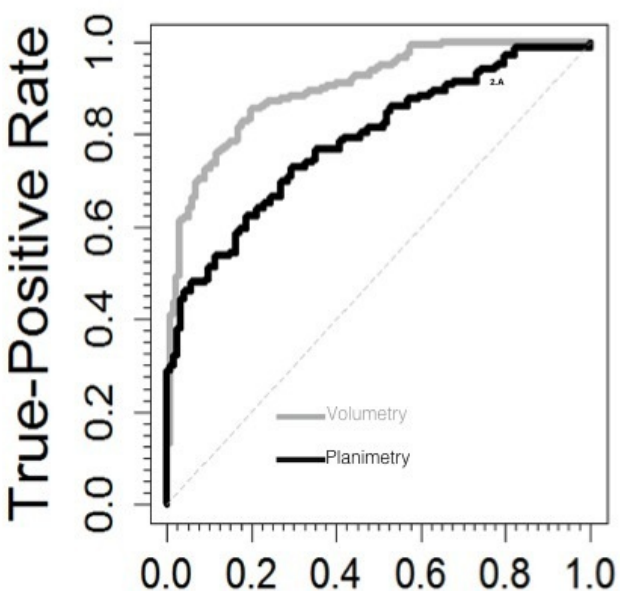

False-Positive Rate

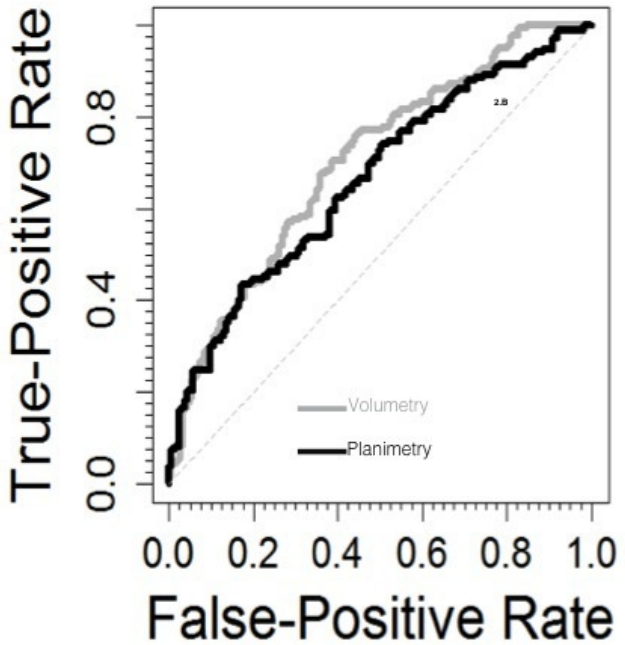

False-Positive Rate

\section{FIGURE 1: ROC Curves}

ROC curves in the differential diagnosis of $A D$ vs controls (left) and $A D$ vs $M C l$ (right).

\section{Discussion}

Despite the strong correlation to severity of AD pathology and inclusion in the new diagnostic criteria [14, 40], the measurement of MTA is not widely used in daily clinical practice as a criterion in the diagnosis of prodromal and probable AD. This is mainly because the methods available to date are sophisticated and difficult to implement in clinical practice (volumetric methods) or lack objectivity (VR). Planimetric methods, being objective and easy to implement, might be an alternative. However, no study has compared the performance of these methods against volumetric methods in the diagnosis of $\mathrm{AD}$ to date.

In this study, the means of both methods were significantly different between AD and the other two diagnostic groups. Rates of hippocampal atrophy were similar to rates reported in other studies, about 1.0-1.5\%/year in healthy aging, above 1.5\%/year in mild cognitive impairment, and around $2 \% /$ year in $\mathrm{AD}[2,4]$.

In the differential diagnosis of $\mathrm{AD}$ from controls, 3D-yrA-H performed significantly better than 2D-yrA-MTL while differences were not statistically significant in the differential diagnosis of $\mathrm{AD}$ against MCI. Thus, 3D-yrA-H is superior to 2D-yrA-MTL in the diagnosis of AD.

Thus, we can conclude volumetric measures are more accurate in terms of sensitivity and specificity than planimetric measures in the diagnosis of AD. However, planimetric techniques have several advantages over volumetry from the clinician's point of view. One of the strengths of planimetry methods is that they can be measured using almost any DICOM visualization software commonly used by clinicians or radiologists to visualize medical images worldwide. Most of these software packages are intuitive and require little or no training at all. Learning to trace the areas needed to compute the 2D-yrA-MTL is quick and easy, even for naive tracers [27]. Even more importantly, tracing these areas has good intra- and inter-rater reproducibility [27-28]. 
The main limitation of the 2D-yrA-MTL is that scoring is based on measurements performed on a single coronal slice, thereby providing a limited perspective of overall brain pathology. It is also expected that other conditions affecting the ventricular morphology, such as hydrocephalus, will probably alter the interpretation of the 2D-yrA-MTL.

This study has some limitations. First, we have not taken into account the ApoE genotype of subjects, and therefore, we have not adjusted the analysis using this parameter (when ApoE genotype is a moderator of brain atrophy) [4]. As a result, there might be a bias in terms of a different distribution of ApoE genotypes between groups. Secondly, we are comparing a manual procedure for planimetric measures with an automatic procedure for volumetric measures. We know hippocampus atrophy rate estimates are greater when assessed with manual than with automatic segmentation, such as FreeSurfer [2]. Here, we are comparing results of manual procedures for planimetry measures with automatic procedures for volumetry measures when they do not estimate atrophy to the same extent. We also know these differences are related to the subregions included in each method rather than to the accuracy of estimation [2]. Finally, both methods used in this study are focused on the same region (the MTL), but the structures covered are largely different. The planimetric measures include the hippocampi and the parahippocampal gyri while the volumetric measures include the hippocampi only. Consequently, we assume from the start that the anatomical extension covered by these methods is not equivalent.

\section{Conclusions}

Automated volumetry of the hippocampus is superior to the 2D-yrAMTL in the diagnosis of AD. Nevertheless, planimetry is a simpler method that could be easily implemented in clinical practice when volumetry is not available.

\section{Additional Information \\ Disclosures}

Human subjects: Consent was obtained by all participants in this study. Animal subjects: All authors have confirmed that this study did not involve animal subjects or tissue. Conflicts of interest: In compliance with the ICMJE uniform disclosure form, all authors declare the following: Payment/services info: All authors have declared that no financial support was received from any organization for the submitted work. Financial relationships: All authors have declared that they have no financial relationships at present or within the previous three years with any organizations that might have an interest in the submitted work. Other relationships: All authors have declared that there are no other relationships or activities that could appear to have influenced the submitted work.

\section{Acknowledgements}

AddNeuroMed is supported by InnoMed (Innovative Medicines in Europe), an integrated project funded by the European Union of the Sixth Framework Program priority FP6-2004LIFESCIHEALTH-5, Life Sciences, Genomics and Biotechnology for Health.

\section{References}

1. Jack CR Jr, Petersen RC, Xu YC, Waring SC, O'Brien PC, Tangalos EG, Smith GE, Ivnik RJ, Kokmen E: Medial temporal atrophy on MRI in normal aging and very mild Alzheimer's disease. Neurology. 1997, 49:786-94. 10.1212/WNL.49.3.786

2. Fraser MA, Shaw ME, Cherbuin N: A systematic review and meta-analysis of longitudinal hippocampal atrophy in healthy human ageing. Neuroimage. 2015, 112:364-74.

10.1016/j.neuroimage.2015.03.035 
3. Braak H, Braak E: Neuropathological staging of Alzheimer-related changes. Acta Neuropathol. 1991, 82:239-59. 10.1007/BF00308809

4. Hossein Tabatabaei-Jafari, Marnie E. Shaw, Nicolas Cherbuin: Cerebral atrophy in mild cognitive impairment: A systematic review with meta-analysis. Alzheimer's \& Dementia: Diagnosis, Assessment \& Disease Monitoring. 2015, 1:487-504. 10.1016/j.dadm.2015.11.002

5. Fennema-Notestine C, McEvoy LK, Hagler DJ Jr, Jacobson MW, Dale AM, The Alzheimer's Disease Neuroimaging Initiative: Structural neuroimaging in the detection and prognosis of pre-clinical and early AD. Behav Neurol. 2009, 21:3-12. 10.3233/BEN-2009-0230

6. Jack CR Jr, Shiung MM, Gunter JL, O'Brien PC, Weigand SD, Knopman DS, Boeve BF, Ivnik RJ, Smith GE, Cha RH, Tangalos EG, Petersen RC: Comparison of different MRI brain atrophy rate measures with clinical disease progression in AD. Neurology. 2004, 62:591-600. 10.1212/01.WNL.0000110315.26026.EF

7. Killiany RJ, Hyman BT, Gomez-Isla T, Moss MB, Kikinis R, Jolesz F, Tanzi R, Jones K, Albert MS: MRI measures of entorhinal cortex vs hippocampus in preclinical AD . Neurology. 2002, 58:1188-96. 10.1212/WNL.58.8.1188

8. Varon D, Loewenstein DA, Potter E, Greig MT, Agron J, Shen Q, Zhao W, Celeste Ramirez M, Santos I, Barker W, Potter H, Duara R: Minimal atrophy of the entorhinal cortex and hippocampus: progression of cognitive impairment. Dement Geriatr Cogn Disord. 2001, 31:276-83. 10.1159/000324711

9. McEvoy LK, Fennema-Notestine C, Roddey JC, Hagler DJ Jr, Holland D, Karow DS, Pung CJ, Brewer JB, Dale AM; Alzheimer's Disease Neuroimaging Initiative: Alzheimer disease: quantitative structural neuroimaging for detection and prediction of clinical and structural changes in mild cognitive impairment. Radiology. 2009, 251:195-205.

10.1148/radiol.2511080924

10. Cardenas VA, Chao LL, Studholme C, Yaffe K, Miller BL, Madison C, Buckley ST, Mungas D, Schuff N, Weiner MW: Brain atrophy associated with baseline and longitudinal measures of cognition. Neurobiol Aging. 2011, 32:572-80. 10.1016/j.neurobiolaging.2009.04.011

11. Westman E, Simmons A, Zhang Y, Muehlboeck JS, Tunnard C, Liu Y, Collins L, Evans A, Mecocci P, Vellas B, Tsolaki M, Kłoszewska I, Soininen H, Lovestone S, Spenger C, Wahlund LO; AddNeuroMed consortium: Multivariate analysis of MRI data for Alzheimer's disease, mild cognitive impairment and healthy controls. Neuroimage. 2011, 54:1178-87.

10.1016/j.neuroimage.2010.08.044

12. Liu Y, Paajanen T, Zhang Y, Westman E, Wahlund LO, Simmons A, Tunnard C, Sobow T, Mecocci P, Tsolaki M, Vellas B, Muehlboeck S, Evans A, Spenger C, Lovestone S, Soininen H; AddNeuroMed Consortium: Analysis of regional MRI volumes and thicknesses as predictors of conversion from mild cognitive impairment to Alzheimer's disease. Neurobiol Aging. 2010, 31:1375-85. 10.1016/j.neurobiolaging.2010.01.022

13. Westman E, Simmons A, Muehlboeck JS, Mecocci P, Vellas B, Tsolaki M, Kłoszewska I, Soininen H, Weiner MW, Lovestone S, Spenger C, Wahlund LO; AddNeuroMed consortium; Alzheimer's Disease Neuroimaging Initiative: AddNeuroMed and ADNI: similar patterns of Alzheimer's atrophy and automated MRI classification accuracy in Europe and North America. Neuroimage. 2011, 58:818-28. 10.1016/j.neuroimage.2011.06.065

14. Sperling RA, Aisen PS, Beckett LA, Bennett DA, Craft S, Fagan AM, Iwatsubo T, Jack CR Jr, Kaye J, Montine TJ, Park DC, Reiman EM, Rowe CC, Siemers E, Stern Y, Yaffe K, Carrillo MC, Thies B, Morrison-Bogorad M, Wagster MV, Phelps CH: Toward defining the preclinical stages of Alzheimer's disease: recommendations from the National Institute on Aging-Alzheimer's Association workgroups on diagnostic guidelines for Alzheimer's disease. Alzheimers Dement. 2011, 7:280-92. 10.1016/j.jalz.2011.03.003

15. Rathakrishnan BG, Doraiswamy PM, Petrella JR: Science to practice: translating automated brain MRI volumetry in Alzheimer's disease from research to routine diagnostic use in the work-up of dementia. Front Neurol. 2014, 4:216. 10.3389/fneur.2013.00216

16. Lehmann M1, Douiri A, Kim LG, Modat M, Chan D, Ourselin S, Barnes J, Fox NC: Atrophy patterns in Alzheimer's disease and semantic dementia: a comparison of FreeSurfer and manual volumetric measurements. Neuroimage. 2010, 49:2264-74.

10.1016/j.neuroimage.2009.10.056

17. Kovacevic S, Rafii MS, Brewer JB; Alzheimer's Disease Neuroimaging Initiative: Highthroughput, fully automated volumetry for prediction of MMSE and CDR decline in mild cognitive impairment. Alzheimer Dis Assoc Disord. 2009, 23:139-45. 


\subsection{7/WAD.0b013e318192e745}

18. Morra JH, Tu Z, Apostolova LG, Green AE, Avedissian C, Madsen SK, Parikshak N, Hua X, Toga AW, Jack CR Jr, Weiner MW, Thompson PM; Alzheimer's Disease Neuroimaging Initiative: Validation of a fully automated 3D hippocampal segmentation method using subjects with Alzheimer's disease mild cognitive impairment, and elderly controls. Neuroimage. 2008, 43:59-68. 10.1016/j.neuroimage.2008.07.003

19. Brewer JB, Magda S, Airriess C, Smith ME: Fully-automated quantification of regional brain volumes for improved detection of focal atrophy in Alzheimer disease. AJNR Am J Neuroradiol. 2009, 30:578-80. 10.3174/ajnr.A1402

20. Pereira JB, Cavallin L, Spulber G, Aguilar C, Mecocci P, Vellas B, Tsolaki M, Kłoszewska I, Soininen H, Spenger C, Aarsland D, Lovestone S, Simmons A, Wahlund LO, Westman E; AddNeuroMed consortium and for the Alzheimer's Disease Neuroimaging Initiative: Influence of age, disease onset and ApoE4 on visual medial temporal lobe atrophy cut-offs. J Intern Med. 2014, 275:317-30. 10.1111/joim.12148

21. Scheltens P, Pasquier F, Weerts JG, Barkhof F, Leys D: Qualitative assessment of cerebral atrophy on MRI: inter- and intra-observer reproducibility in dementia and normal aging. Eur Neurol. 1997, 37:95-99. 10.1159/000117417

22. Scheltens P, Launer LJ, Barkhof F, Weinstein HC, van Gool WA: Visual assessment of medial temporal lobe atrophy on magnetic resonance imaging: interobserver reliability. J Neurol. 1995, 242:557-60. 10.1007/BF00868807

23. Dahlbeck JW, McCluney KW, Yeakley JW, Fenstermacher MJ, Bonmati C, Van Horn G 3rd, Aldag J: The interuncal distance: a new MR measurement for the hippocampal atrophy of Alzheimer disease. AJNR Am J Neuroradiol. 1991, 12:931-32.

24. Erkinjuntti T, Lee DH, Gao F, Steenhuis R, Eliasziw M, Fry R, Merskey H, Hachinski VC: Temporal lobe atrophy on magnetic resonance imaging in the diagnosis of early Alzheimer's disease. Arch Neurol. 1993, 50:305-10. 10.1001/archneur.1993.00540030069017

25. Frisoni GB, Geroldi C, Beltramello A, Bianchetti A, Binetti G, Bordiga G, DeCarli C, Laakso MP, Soininen H, Testa C, Zanetti O, Trabucchi M: Radial width of the temporal horn: a sensitive measure in Alzheimer disease. AJNR Am J Neuroradiol. 2002, 23:35-47.

26. Menéndez-González M, López-Muñiz A, Vega JA, Salas-Pacheco JM, Arias-Carrión O: MTA index: a simple 2D-method for assessing atrophy of the medial temporal lobe using clinically available neuroimaging. Front Aging Neurosci. 2014, 6:23. 10.3389/fnagi.2014.00023

27. Conejo Bayón F, Maese J, Fernandez Oliveira A, Mesas T, Herrera de la Llave E, Álvarez Avellón T, Menéndez-González M: Feasibility of the medial temporal lobe atrophy index (MTAi) and derived methods for measuring atrophy of the medial temporal lobe. Front Aging Neurosci. 2014, 6:305. 10.3389/fnagi.2014.00305

28. Menéndez-González M, Fernández Oliveira A, Conejo Bayón F, Maese J, Mesas Uzal T, Herrera de la Llave E, Álvarez Avellón T: Planimetry of the medial temporal lobe: a feasible method for supporting the diagnosis of Alzheimer's disease in clinical practice. Neurology and Neuroscience. 2015, 1:8. 10.3823/355

29. Falahati F, Fereshtehnejad SM, Religa D, Wahlund LO, Westman E, Eriksdotter M: The use of MRI, CT and lumbar puncture in dementia diagnostics: data from the SveDem Registry. Dement Geriatr Cogn Disord. 2015, 39:81-91. 10.1159/000366194

30. Davies RR, Scahill VL, Graham A, Williams GB, Graham KS, Hodges JR: Development of an MRI rating scale for multiple brain regions: comparison with volumetrics and with voxelbased morphometry. Neuroradiology. 2009, 51:491-503. 10.1007/s00234-009-0521-z

31. Bresciani L, Rossi R, Testa C, Geroldi C, Galluzzi S, Laakso MP, Beltramello A, Soininen H, Frisoni GB: Visual assessment of medial temporal atrophy on MR films in Alzheimer's disease: comparison with volumetry. Aging Clin Exp Res. 2005, 17:8-13. 10.1007/BF03337714

32. Wahlund LO, Julin P, Johansson SE, Scheltens P: Visual rating and volumetry of the medial temporal lobe on magnetic resonance imaging in dementia: a comparative study. J Neurol Neurosurg Psychiatry. 2000, 69:630-35. 10.1136/jnnp.69.5.630

33. Vermersch P, Leys D, Scheltens P, Barkhof F: Visual rating of hippocampal atrophy: correlation with volumetry. J Neurol Neurosurg Psychiatry. 1994, 57:1015. 10.1136/jnnp.57.8.1015

34. Liu Y, Paajanen T, Zhang Y, Westman E, Wahlund LO, Simmons A, Tunnard C, Sobow T, Mecocci P, Tsolaki M, Vellas B, Muehlboeck S, Evans A, Spenger C, Lovestone S, Soininen H; AddNeuroMed Consortium: Combination analysis of neuropsychological tests and structural 
MRI measures in differentiating AD, MCI and control groups--the AddNeuroMed study. Neurobiol Aging. 2011, 32:1198-1206. 10.1016/j.neurobiolaging.2009.07.008

35. Lovestone S, Francis P, Strandgaard K: Biomarkers for disease modification trials--the innovative medicines initiative and AddNeuroMed. J Nutr Health Aging. 2007, 11:359-61.

36. Simmons A, Westman E, Muehlboeck S, Mecocci P, Vellas B, Tsolaki M, Kłoszewska I, Wahlund LO, Soininen H, Lovestone S, Evans A, Spenger C: The AddNeuroMed framework for multi-centre MRI assessment of Alzheimer's disease: experience from the first 24 months. Int J Geriatr Psychiatry. 2011, 23:75-82. 10.1002/gps.2491

37. Fischl B, Salat DH, Busa E, Albert M, Dieterich M, Haselgrove C, van der Kouwe A, Killiany R, Kennedy D, Klaveness S, Montillo A, Makris N, Rosen B, Dale AM: Whole brain segmentation: automated labeling of neuroanatomical structures in the human brain. Neuron. 2002, 33:34155. 10.1016/S0896-6273(02)00569-X

38. Dale AM, Fischl B, Sereno MI: Cortical surface-based analysis. I. Segmentation and surface reconstruction. Neuroimage. 1999, 9:179-94. 10.1006/nimg.1998.0395

39. Menendez M, Arias-Carrión O: Indices of regional brain atrophy: Formulae and nomenclature. Cureus. 2015, 7 :e295. 10.7759/cureus.295

40. McKhann GM, Knopman DS, Chertkow H, Hyman BT, Jack CR Jr, Kawas CH, Klunk WE, Koroshetz WJ, Manly JJ, Mayeux R, Mohs RC, Morris JC, Rossor MN, Scheltens P, Carrillo MC, Thies B, Weintraub S, Phelps CH: The diagnosis of dementia due to Alzheimer's disease: recommendations from the National Institute on Aging-Alzheimer's Association workgroups on diagnostic guidelines for Alzheimer's disease. Alzheimers Dement. 2011, 7:263-69. 10.1016/j.jalz.2011.03.005 